\title{
Intrauterine Growth Restriction Affects the Preterm Infant's Hippocampus
}

\author{
GREGORY A. LODYGENSKY, MOHAMMED L. SEGHIER, SIMON K. WARFIELD, CRISTINA BORRADORI TOLSA, \\ STEPHANE SIZONENKO, FRANÇOIS LAZEYRAS, AND PETRA S. HÜPPI
}

\begin{abstract}
Department of Pediatrics [G.A.L.], Washington University, St Louis, Missouri 63110; Wellcome Trust Centre for Neuroimaging [M.L.S.], University College London, London WC1N 3BG, United Kingdom; Departments of Radiology [S.K.W.] and Neurology [P.S.H.], Harvard Medical School, Boston, Massachusetts 02115; Departments of Pediatrics [C.B.T., S.S., P.S.H.], and Radiology [F.L.], University Hospital of Geneva, 1211 Geneva, Switzerland
\end{abstract}

\begin{abstract}
The hippocampus is known to be vulnerable to hypoxia, stress, and undernutrition, all likely to be present in fetal intrauterine growth restriction (IUGR). The effect of IUGR in preterm infants on the hippocampus was studied using 3D magnetic resonance imaging at term-equivalent age Thirteen preterm infants born with IUGR after placental insufficiency were compared with 13 infants with normal intrauterine growth age matched for gestational age. The hippocampal structural differences were defined using voxel-based morphometry and manual segmentation. The specific neurobehavioral function was evaluated by the Assessment of Preterm Infants' Behavior at term and at 24 mo of corrected age by a Bayley Scales of Infant and Toddler Development. Voxel-based morphometry detected significant gray matter volume differences in the hippocampus between the two groups. This finding was confirmed by manual segmentation of the hippocampus with a reduction of hippocampal volume after IUGR. The hippocampal volume reduction was further associated with functional behavioral differences at term-equivalent age in all six subdomains of the Assessment of Preterm Infants' Behavior but not at 24 mo of corrected age. We conclude that hippocampal development in IUGR is altered and might result from a combination of maternal corticosteroid hormone exposure, hypoxemia, and micronutrient deficiency. (Pediatr Res 63: 438-443, 2008)
\end{abstract}

$\mathrm{O}$ the 4 million babies born annually in the United States, $12 \%(\sim 476,000)$ are born prematurely. Of these, $5-12 \%$ have additionally experienced intrauterine growth restriction (IUGR) and are born with inappropriately low birth weight (1). Preterm infants with additional IUGR are at highest risk for long-term morbidities, including developmental disabilities such as cerebral palsy, mental retardation, and a wide spectrum of learning disabilities and behavior disorders $(2-7)$. The specific nature of these developmental disabilities and the underlying neuropathology are unknown. In vivo 3D magnetic resonance imaging (MRI) has recently opened up the possibility of determining the impact of prematurity on the

Received November 28, 2007; accepted December 18, 2007

Correspondence: Gregory Lodygensky, M.D., Department of Pediatrics, Washington University, 8th floor, NWT, One Children's Place, St. Louis, MO 63110; e-mail: lodygensky_g@kids.wustl.edu

Supported by the Swiss National Science Foundation, grants No 32-56927.99; 32102127 (PSH) and in part by NIH grant P41 RR13218, by a research grant from the Whitaker Foundation (SKW), by a research grant from CIMIT (SKW) and by NIH grants R03 CA126466 (SKW) and R01 RR021885 (SKW).

DOI: 10.1203/PDR.0b013e318165c005 structural development of the brain (8-11). Brain structural changes after IUGR in the human have been described with an overall reduction of cortical gray matter volume in IUGR preterm infants throughout the neonatal period (12). Effects of prematurity on the structural development of specific brain regions have recently been described by similar 3D-MRI methods (13). Among different cortical brain regions, the hippocampus formation seems to be least genetically regulated $(14,15)$ and most prone to developmental and environmental influences. The hippocampus is known for its crucial role in cognitive function such as memory and learning. It is vulnerable to hypoxia, stress hormones, undernutrition, and alteration of micronutrient supply, all likely to be present in pregnancies complicated by IUGR (16). IUGR, in an animal model was shown to induce a loss of neuronal volume and number in the cerebellum and hippocampus $(17,18)$.

With the ongoing intense research on neuroprotective strategies for the high-risk newborn, it is important to better define the impact of adverse fetal environment resulting in IUGR on the development of brain structure and function. Given the vulnerability of the hippocampus to conditions associated with IUGR, we hypothesized that hippocampal development was affected by IUGR in human preterm newborns. To address this hypothesis we used MRI with advanced image analysis techniques to study preterm infants with and without IUGR at term-equivalent age $(8,19)$. A combined approach with raterindependent voxel-based morphometry (VBM) (20) and manual segmentation was applied to define gray matter volume differences in the region of the hippocampal formation. We further hypothesized that functional development at term age would be affected by IUGR. To address this secondary hypothesis, infants were evaluated by a quantitative neurobehavioral assessment scale for preterm infants behavior at term age and a quantitative neurodevelopmental assessment at 24 mo of corrected age.

\footnotetext{
Abbreviations: APIB, assess of preterm infants' behavior; FOV, field of view; FWHM, full width at half maximum; IUGR, intrauterine growth restriction; MRI, magnetic resonance imaging; NEC, necrotizing enterocolitis; RDS, respiratory distress syndrome; RI, resistance index; S/D, systolic/ diastolic velocities; TE, echo time; TR, repetition time; VBM, voxel-based morphometry; WISC, Wechsler Intelligence Scale for Children (WISC)
} 


\section{MATERIALS AND METHODS}

Subjects. Premature infants born with IUGR secondary to placental insufficiency were recruited for MRI studies. The medical ethical review board of our hospital approved the study. Written informed consent was obtained from all the parents. Patients were recruited when defined to be IUGR by fetal measurements between 20 and $36 \mathrm{wk}$ of pregnancy and having abnormal Doppler flow values measured within the umbilical artery. They were matched for gestational age at birth with preterm infants with an appropriatefor-gestational-age growth and normal flow in the umbilical artery. The presence of placental insufficiency was defined as a resistance to arterial umbilical flow higher than the 95th percentile measured by two indexes (resistance index (RI) and systolic/diastolic velocities (S/D)) within one (the last) or several measurements (21).

Our study population included 26 preterm infants born between September 2001 and August 2004 in Geneva, Switzerland. Thirteen IUGR infants $(1140 \pm 265 \mathrm{~g})$ with a mean gestational age at birth of $32.1 \pm 2.5$ wk were compared with 13 infants matched for gestational age with appropriate weight for gestational age $(1690 \pm 440 \mathrm{~g})$ with a mean gestational age at birth of $32 \pm 2.3$ wk (Table 1)The MRI and the Assessment of Preterm Infants' Behavior (APIB) were carried out at term-equivalent age (IUGR 40.2 \pm 0.7 wk; controls $40.3 \pm 1.1 \mathrm{wk})$. There was no statistical difference in the male/female ratio between the two groups. Head circumference at birth was different in the two groups (IUGR $27.1 \pm 2.2 \mathrm{~cm}$, controls $29.4 \pm 2.2 \mathrm{~cm}, p=$ 0.014). Primary adaptation was similar in both groups with a mean Apgar at 5 min of $9.6 \pm 0.5$ in the IUGR and $9 \pm 1.3$ in the controls and a $\mathrm{pH}>7.1$ in all the infants. Infants included in the study were free of cerebral pathologies diagnosed by ultrasound or by MRI. There was no difference in the initial neonatal illness severity between the two groups and dosages of antenatal steroids as given in Table 1 . No infant in either group received postnatal steroids. The infants studied were free of major neonatal complications such as severe respiratory distress syndrome (RDS) and necrotizing enterocolitis (NEC).

Imaging protocol. MRI was performed on $1.5 \mathrm{~T}$ magnets (1.5 Tesla Marconi/Philips MR systems). The protocol consisted of a 3D fast-gradient echo sequence performed with coronal slices of $1.5 \mathrm{~mm}$ (repetition time $(\mathrm{TR})=15 \mathrm{~ms}$, echo time (TE) $=4.4 \mathrm{~ms}$, Flip angle 25, field of view (FOV) $18 \mathrm{~cm}$ ) and a double echo (T2-and proton-density) fast-spin echo sequence with coronal slices of $1.5 \mathrm{~mm}$ and an in plane resolution of $0.703 \times 0.703 \mathrm{~mm}$ $(\mathrm{TR}=3500 \mathrm{~ms}, \mathrm{TE}=30 / 150 \mathrm{~ms}$, interleaved, no gap acquisition, FOV 18 $\mathrm{cm})$. The infants were positioned on a vacuum pillow inside the scanner and monitored with pulse oximetry (Maglife, Schiller AG). Earmuffs (Natus Medical Inc., San Carlos, CA) were used to minimize noise exposure. No sedation was used.

Image analysis. Postacquisition image processing started with a rigid body registration (22) of T2-weighted coronal images and proton density images with corresponding T1-weighted coronal images. The determination of brain tissue volumes was then assessed using the $k$-NN classification algorithm on the three coregistered channels (T2-weighted, proton density, and T1 weighted). The algorithm included an elastic matching with an anatomical template including the basal ganglia and the brainstem $(8,19)$ SPM2 software (Wellcome Department of Cognitive Neurology, London, UK) was used for VBM. T2-weighted images were normalized, using an affine transformation, on a T2-weighted template created from 14 newborns not included in the present study, thus correcting for global variation in brain volume. The transformation matrix was then applied to the gray matter tissue class

Table 1. Demographic details

\begin{tabular}{lcc}
\hline & $\begin{array}{c}\text { Preterm with } \\
\text { IUGR preterm } \\
\text { infants }(n=13)\end{array}$ & $\begin{array}{c}\text { growth } \\
(n=13)\end{array}$ \\
\hline Mean birth weight $(\mathrm{g}) \pm \mathrm{SD}$ & $1140 \pm 265$ & $1690 \pm 440^{*}$ \\
Mean gestation at birth (wk) $\pm \mathrm{SD}$ & $32.1 \pm 2.5$ & $32 \pm 2.3$ \\
Mean gestational age at MRI and & $40.2 \pm 0.7$ & $40.3 \pm 1.1$ \\
$\quad$ APIB (wk) \pm SD & $23.1 \% \dagger$ & $53.8 \% \dagger$ \\
Boys & $76.9 \% \dagger$ & $46.2 \% \dagger$ \\
Girls & $27.1 \pm 2.2$ & $29.4 \pm 2.2^{*}$ \\
Head circumference $(\mathrm{cm})$ & 53.8 & 84.6 \\
Prenatal corticosteroid treatment $(\%)$ & & \\
\hline
\end{tabular}

$* p<0.05$ for comparison of IUGR preterm $v s$. preterm with appropriate growth.

$\dagger$ Fisher's exact test for boy/girl ratio $p=0.23$. extracted by $k$-NN with voxel sizes of $2 \times 2 \times 2 \mathrm{~mm}$. The spatially normalized gray matter tissue class was then smoothed with a $4 \mathrm{~mm}$ full width at half maximum (FWHM) isotropic Gaussian kernel to create a spectrum of continuous gray matter values needed for the statistical analyses. A twosample paired $t$ test with a level of $p$ set $<0.005$ uncorrected was used for group comparison in the area of the hippocampus. A small volume correction with a radius of $4 \mathrm{~mm}$ (corresponding to the radius of the hippocampus) was used to correct for multiple comparisons. The eventual effects of interest found by VBM analysis are referred to as "gray matter volume" differences, based on the facts that i) the output of gray matter by $k$-NN is a binary mask representing the presence or not of gray matter at the voxel level; ii) the sum of binary values indicates the gray matter volume for a given region and a given subject; and iii) the statistical differences at the group level reflect the differences in the volume of gray matter between the two groups.

To manually segment the hippocampus, the software 3D Slicer (www. slicer.org) was used to visualize MRI slices with its superimposed segmentation in the three orthogonal planes. The T2-weighted images were used to trace the hippocampus. The tracing guidelines used in this study were published elsewhere (23-25). Manual segmentation started on coronal slices. The boundaries of the head and tail of the hippocampus were outlined on the sagittal plane. Once the segmentation was achieved, a 3D reconstruction allowed quality assessment of the segmentation (Fig. 1). Hippocampal volume was determined by summation of voxels. Intraobserver variability calculated on three hippocampal volumes segmented twice was $3.4 \%$.

Neurobehavioral assessment. The APIB assessment tool (26) is a modification of the standardized Brazelton Neonatal Behavioral Assessment Scale (27). It was used to evaluate brain functioning in the neonatal period. Quantification includes measurement of level of differentiation and modulation of various behavioral systems namely: 1) autonomic, 2) motor, 3) state, 4) attention-interaction, 5) self-regulation, 6) examiner facilitation necessary to regulate the preterm infant's behavior. All system scores range from 1-9, 1 corresponding to best performance and 9 to compromised performance.

The statistical Wilcoxon signed ranks test was used to compare the IUGR preterm children matched by gestational age with the control preterm group; this statistical approach was used to control for the known effect of prematurity itself on hippocampal growth $(28-30)$. All statistical procedures were performed with SPSS version 11 (SPSS, Chicago, IL).

Neurodevelopmental outcome was assessed in a subset of patients with the Bayley Scales of Infant and Toddler Development, Second Edition (Bayley II), which yield a mental developmental index (MDI) and psychomotor developmental index (both with a mean of 100 and an SD of 15) ageequivalent scores at 24 mo corrected for gestational age. Only the MDI is reported in this study. Nine patients were lost to follow-up.

\section{RESULTS}

Early quantitative volumetric MR analysis was performed at term age in thirteen IUGR premature infants and thirteen premature control infants with appropriate for gestation intrauterine growth. A detailed neurobehavioral assessment was undertaken

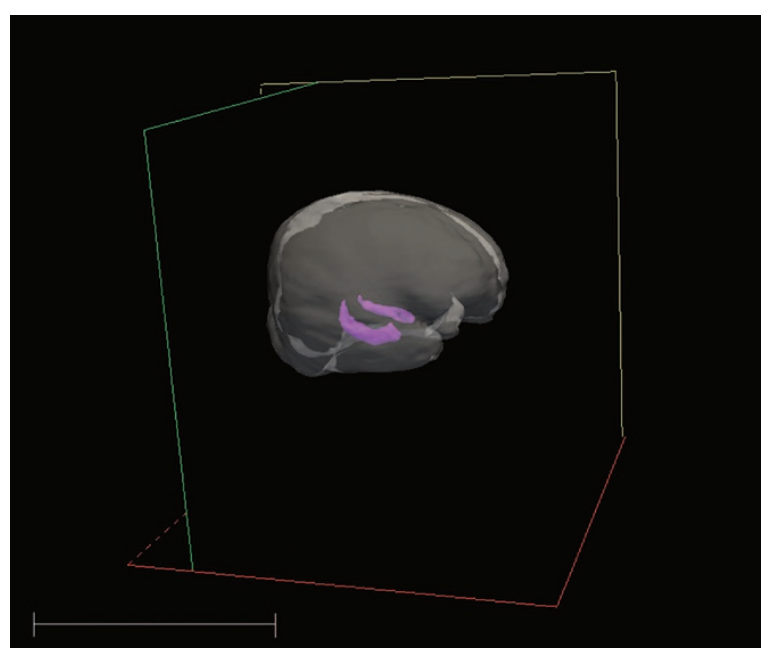

Figure 1. 3D representation of both hippocampi superimposed with a $3 \mathrm{D}$ representation of the intracranial cavity. Bar $=12 \mathrm{~cm}$. 
at term age in all infants and seventeen infants were evaluated for neurodevelopmental outcome at 24 mo of age.

VBM comparing IUGR with control premature infants' gray matter volumes: hippocampus. Using rater-independent VBM on normalized cortical gray matter, IUGR in preterm infants was shown to be associated with a significant reduction of gray matter volume of both hippocampi (right hippocampus $p$ uncorrected $0.003, p$ FDR-corrected 0.022; left hippocampus $p$ uncorrected $0.001, p$ FDR-corrected 0.013 , using a small volume correction) (Fig. 2, Table 2).

Manual segmentation comparing IUGR with control premature infants. Gray matter volumes: hippocampus. We found similar results when manually segmenting the hippocampus on T2-weighted images. Total hippocampal volume was found to be significantly affected by IUGR (IUGR: 1.94 $\mathrm{mL} \pm 0.24$, control: $2.14 \mathrm{~mL} \pm 0.21, p=0.009)$. When analyzed separately, left hippocampus $(p=0.005)$ and right hippocampal volume $(p=0.039)$ were affected equally by placental insufficiency (Table 3 ).

Right-greater-than-left asymmetry of hippocampal structures was found (Wilcoxon signed ranks test in the control group: $p=$
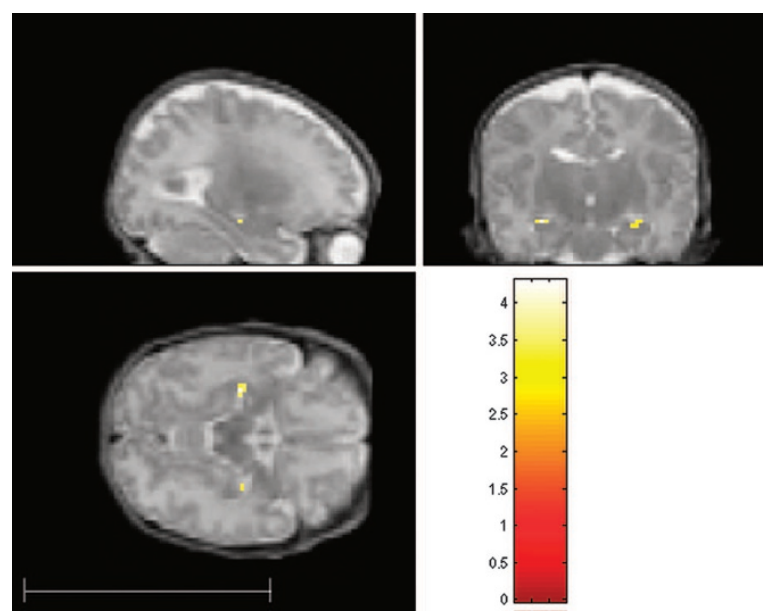

Figure 2. Effect of intrauterine growth restriction on hippocampal formation. Voxel-based morphometry in the region of interest with a mask on the rest of the brain. The results are superimposed on a normalized T2-weighted image series. Bar $=12 \mathrm{~cm}$.
0.006 and in the IUGR group: $p=0.001)$, ranging between $7.4 \%$ in the control group and $9.1 \%$ in the IUGR group.

Hippocampal right-greater-than-left asymmetry was not affected by IUGR $(p=0.56)$.

Gray matter volumes: hippocampus, total brain, correlations to birth weight. Hippocampal volume correlated very highly with overall cortical gray matter (Pearson correlation $0.774, p<0.001)$. A significant correlation was found between birth weight and hippocampal volume (Pearson Correlation $0.507, p=0.008$ ). Hippocampal volume can be calculated using the following linear regression: hippocampal volume $=0.0003 \times$ birth weight $+1.66, R^{2}=0.2568$ (Fig. 3 ). Birth weight correlated also, but to a lesser degree, with cortical gray matter (Pearson Correlation 0.413, $p=0.036$ ).

Functional outcome comparing IUGR with control premature infants. In terms of assessment of the functional maturation, the APIB shows less mature scores in the IUGR infants compared with control infants (autonomic: $Z=-2.75$, $p=0.006$; motor: $Z=-2.71, p=0.007$; state $Z=-2.09$, $p=0.037$; attention-interaction: $Z=-2.93, p=0.003$; self-regulation: $Z-2.35, p=0.019$; examiner facilitation: $Z-2.12, p=0.034$ ) (Table 4).

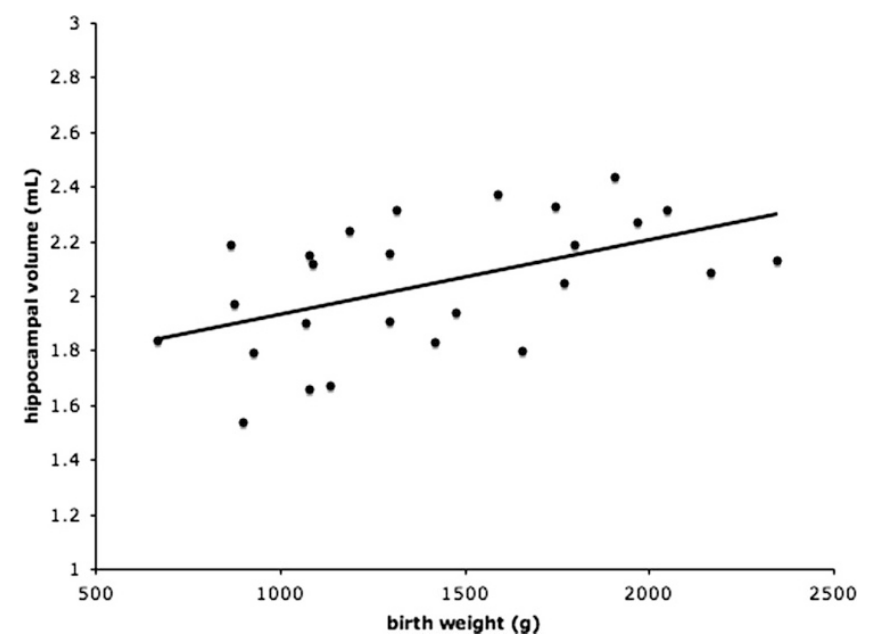

Figure 3. Scatterplot of the birth weight effect on hippocampal volume in preterm children at term, with a best-fit regression line (hippocampal volume $0.0003 \times$ birth weight $+1.66 ; R^{2}=0.2568$ )

Table 2. Effect of IUGR on hippocampal volume using voxel based morphometry

\begin{tabular}{|c|c|c|c|c|c|c|c|}
\hline & \multicolumn{2}{|c|}{ Cluster-level } & \multicolumn{2}{|c|}{ Voxel-level } & \multirow[b]{2}{*}{$\mathrm{T}$} & \multirow[b]{2}{*}{$(Z)$} & \multirow[b]{2}{*}{$p$ uncorrected } \\
\hline & $p^{*}$ corrected & $\mathrm{kE}$ & $p$ uncorrected & $p^{*} \mathrm{FDR}-\mathrm{corr}$ & & & \\
\hline Right hippocampus & 0.032 & 4 & 0.158 & 0.022 & 3.37 & 2.77 & 0.003 \\
\hline Left hippocampus & 0.024 & 5 & 0.117 & 0.013 & 4.3 & 3.28 & 0.001 \\
\hline
\end{tabular}

* Corrected $p$ value done using a small volume correction (SVC).

Table 3. Hippocampal volume

\begin{tabular}{|c|c|c|c|c|}
\hline & $\begin{array}{c}\text { Total hippocampal } \\
\text { volume }(\mathrm{mL}) \pm \mathrm{SD}\end{array}$ & $\begin{array}{l}\text { Right hippocampal } \\
\text { volume }(\mathrm{mL}) \pm \mathrm{SD}\end{array}$ & $\begin{array}{l}\text { Left hippocampal } \\
\text { volume }(\mathrm{mL}) \pm \mathrm{SD}\end{array}$ & $\begin{array}{l}\text { Cortical gray matter } \\
\text { volume }(\mathrm{mL}) \pm \mathrm{SD}\end{array}$ \\
\hline $\begin{array}{l}\text { IUGR preterm infants } \\
\quad(n=13)\end{array}$ & $1.94 \pm 0.24$ & $1.02 \pm 0.14$ & $0.92 \pm 0.11$ & $152.44 \pm 21.64$ \\
\hline $\begin{array}{l}\text { Preterm with appropriate } \\
\quad \text { growth }(n=13)\end{array}$ & $2.14 \pm 0.21$ & $1.11 \pm 0.11$ & $1.03 \pm 0.11$ & $180.59 \pm 31.96$ \\
\hline $\begin{array}{l}\text { Wilcoxon Signed Ranks } \\
\text { Test }\end{array}$ & p 0.009 & p 0.039 & $p 0.005$ & $p 0.005$ \\
\hline
\end{tabular}


Table 4. Assessment of preterm infants behavior (APIB) at term age

\begin{tabular}{|c|c|c|c|c|c|c|}
\hline & Autonomic & Motor & State & $\begin{array}{l}\text { Attention- } \\
\text { interaction }\end{array}$ & Self-regulation & $\begin{array}{l}\text { Examiner } \\
\text { facilitation }\end{array}$ \\
\hline IUGR preterm infants & $5.45 \pm 0.57$ & $5.62 \pm 0.8$ & $5.2 \pm 0.68$ & $6.69 \pm 0.79$ & $5.35 \pm 0.74$ & $4.91 \pm 1.13$ \\
\hline $\begin{array}{l}\text { Preterm with } \\
\text { appropriate growth }\end{array}$ & $4.39 \pm 0.76$ & $4.46 \pm 0.93$ & $4.7 \pm 0.64$ & $4.56 \pm 0.94$ & $4.31 \pm 0.84$ & $4.13 \pm 0.89$ \\
\hline $\begin{array}{l}\text { Wilcoxon Signed } \\
\text { Ranks Test }\end{array}$ & $\mathrm{Z}-2.75, p 0.006$ & $\mathrm{Z}-2.71, p 0.007$ & $\mathrm{Z}-2.09, p 0.037$ & $\mathrm{Z}-2.93, p 0.003$ & $\mathrm{Z}-2.35, p 0.019$ & $\mathrm{Z}-2.12, p 0.034$ \\
\hline
\end{tabular}

Long-term functional neurodevelopmental outcome was assessed at 24 mo corrected age in 17 of the 26 infants. IUGR infants had lower mean MDI (IUGR $86.3 \pm 15.6$, controls $94.3 \pm 11.1)$ but this difference did not reach statistical significance $(p=0.32)$. Total hippocampal volume significantly correlated with MDI at 24 mo corrected age (Pearson correlation $0.516, p=0.034$ with a linear regression equation $\mathrm{MDI}=$ $28.36 \times$ hippocampal volume $\left.+34.022, R^{2} 0.2665\right)$ (Fig. 4).

\section{DISCUSSION}

This study shows the impact of adverse fetal environment and IUGR on the development of specific brain structures such as the hippocampus in the preterm newborn, which adds to the earlier published findings of effects on total brain tissue volumes in IUGR infants (12). The study results further indicate a correlation of these specific structural abnormalities with early functional outcomes both at term age and at 24 mo corrected age.

To eliminate observer bias, structural brain analysis was achieved by applying sophisticated image analysis tools such as VBM to in vivo newborn MRI (20). At a $p$ value of 0.005 for group comparison, we found significant reduction of gray matter volume in bilateral hippocampal structures after IUGR and premature birth. Those results remained significant after correction for multiple comparisons. Voxel-based statistical analysis, when assessing large volumes (i.e., whole brain), requires large sample size to be able to identify small changes between groups. To compensate for the total number of patients, we lowered the $p$ value to 0.005 in our VBM analysis, thus reducing the chance for type 2 errors and selected only the region of interest for VBM analysis. The

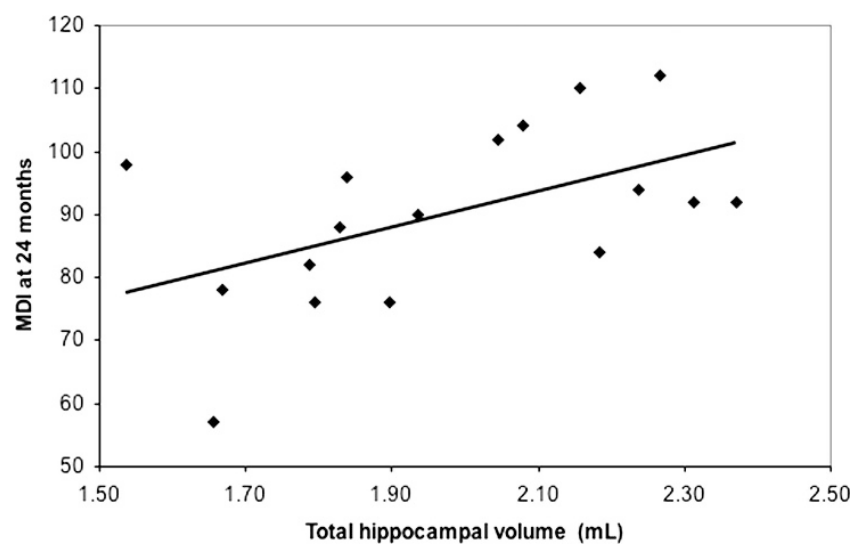

Figure 4. Scatterplot of the total hippocampal volume with the MDI at $24 \mathrm{mo}$ corrected age with a best-fit regression line (MDI $=28.36 \times$ hippocampal volume $+34.022 ; R^{2} 0.2665$ ). major advantage of VBM over standard volumetric assessments for group analysis is the normalization of the image data. The inherent difference in total brain volume between groups is taken into account in our VBM analysis as the brains from both groups are normalized to a common template, therefore assessment of specific brain structures such as the hippocampus has been made possible, independent of overall brain volume.

Moreover, we were able to confirm by an independent image analysis method using manual segmentation that IUGR is associated with a reduction of hippocampal volume in preterm infants when examined at term-equivalent age. The manually edited data were not corrected for head circumference or total brain volume due to the limited number of subjects studied. Caution should therefore be used in assessing the selective effect of IUGR on manually segmented hippocampi. The hippocampal volume reduction is possibly not selectively affected by IUGR but is part of a broader insult affecting weight, head circumference, and cortical gray matter volume, as described earlier.

Hippocampal formation is sensitive to a number of insults, in particular hypoxic conditions and stress hormones. A similar image analysis approach has been used to show decreased gray matter in the hippocampus in posttraumatic stress syndrome in adults (31). VBM was further able to distinguish the effect of prematurity in a group of adolescents with a marked reduction of the left hippocampus and the thalamus (28).

The hippocampus, being a small structure and part of the archicortex, and as such phylogenetically different from the layered neocortex, is shown to be affected by adverse intrauterine environment in a similar way as the neocortex, which has already been shown to be impaired by IUGR (12). The strong correlation between hippocampal volume and cortical volume detected in this study indicates that both structures from the archicortex and the neocortex are affected by conditions associated with IUGR. Birth weight was shown to correlate specifically with hippocampal volume and to a lesser extent to total cortical gray matter volume at term-equivalent age. This association seems to persist as it was also described in school-aged children born preterm (32) showing that birth weight rather than gestational age has a predominant impact on brain development, thus reflecting the importance of the microenvironment in which the fetus develops and its longstanding effects on brain development. We found a rightgreater-than-left asymmetry as described in a cohort of preterm children at $8 \mathrm{y}$ of age (32) that remained unaffected by IUGR. Right-greater-than-left asymmetry in the hippocampal 
volume has been repetitively described in adulthood and was shown to be associated with right-handedness (33).

Those striking volume differences detected by VBM and confirmed by manual segmentation were associated with functional behavioral differences at term age detected by APIB scores. IUGR preterm infants had worse scores in all six subdomains, with more profound differences in attentioninteraction capacity, autonomic, and motor behaviors. The detection of impaired behavioral performance with APIB at term age has been shown to correlate with later neurobehavioral deficits (34) and might therefore be an early expression of functional deficits linked to the structural differences observed in the IUGR group. Long-term neurodevelopmental outcome as assessed by mean MDI scores was not statistically different in IUGR preterm infants from the control group. However, caution should be used when interpreting this finding as $35 \%$ of children were lost to follow up and because the Bayley is not an ideal test to predict deficits in declarative, episodic, spatial, and contextual memory most likely affected by hippocampal dysfunction later in life. Further studies at older age, involving specific memory evaluation and fMRI, would be required to determine the long-term effect of IUGR on specific hippocampal function. A significant correlation was found between the total hippocampal volume at termequivalent and the MDI at 24 mo corrected age. This confirms the relevance of hippocampal volume in relationship to a neurocognitive functioning, which has been described in former preterm infants at $8 \mathrm{y}$ of age where the hippocampal volume correlated with the Wechsler Intelligence Scale for Children (WISC) evaluation scale (32).

Several mechanisms are proposed to explain the increased sensitivity of the hippocampus to conditions that lead to poor intrauterine growth. Fetal hypoxemia induced by uterine artery ligation and hypoxia were both shown to affect the hippocampal neuronal system $(18,35)$. Nutritional deprivation during pregnancy was shown to alter the expression of the placental 11 beta-hydroxysteroid dehydrogenase type 2, an enzyme that clears maternal cortisol, thus exposing the fetus to an excess of corticosteroids known to impair hippocampal growth (36-38). Interestingly, cortisol levels were discovered to remain high in adults born with a low birth weight, suggesting that a deficient fetal environment is able to permanently up-regulate the hypothalamic-pituitary-adrenal axis (39), which might contribute further to postnatally impaired hippocampal formation. A deficiency of micronutrients might further contribute to hippocampal injury. Iron deficiency, for instance, has been shown to be associated with IUGR and causes injury of the CA1 pyramidal neurons (40). Placental insufficiency in humans might induce an actual combination of fetal corticosteroid overexposure, hypoxemia, and micronutrient deficiency, thus exposing the growing brain, and in particular the hippocampus, to potential damage. The question is whether IUGR causes a temporary insult to the hippocampal volume that can be outgrown or causes an irreversible injury that is perpetuated by a longstanding up-regulation of the hypothalamic-pituitary-adrenal axis. Further studies will need to define the long-term effect of IUGR on hippocampal structure and function and its relationship to the emergence of psychiatric disorders in which hippocampal atrophy is one of the most consistent structural features.

Acknowledgments. We thank F. Henri and D. Joliat for technical assistance. We the thank families and infants of the cohort for their participation in this study.

\section{REFERENCES}

1. Hoyert DL, Mathews TJ, Menacker F, Strobino DM, Guyer B 2006 Annual summary of vital statistics: 2004. Pediatrics 117:168-183

2. Hack M, Flannery DJ, Schluchter M, Cartar L, Borawski E, Klein N 2002 Outcomes in young adulthood for very-low-birth-weight infants. N Engl J Med 346:149-157

3. Hack M, Friedman H, Fanaroff AA 1996 Outcomes of extremely low birth weight infants. Pediatrics 98:931-937

4. Allen AS, Barnhart HX 2002 Joint models for toxicology studies with dosedependent number of implantations. Risk Anal 22:1165-1173

5. Hawdon JM, Hey E, Kolvin I, Fundudis T 1990 Born too small—is outcome still affected? Dev Med Child Neurol 32:943-953

6. Hollo O, Rautava P, Korhonen T, Helenius H, Kero P, Sillanpaa M 2002 Academic achievement of small-for-gestational-age children at age 10 years. Arch Pediatr Adolesc Med 156:179-187

7. Kjellmer I, Liedholm M, Sultan B, Wennergren M, Wallin Gotborg C, Thordstein M 1997 Long-term effects of intrauterine growth retardation. Acta Paediatr Suppl 422:83-84

8. Huppi PS, Warfield S, Kikinis R, Barnes PD, Zientara GP, Jolesz FA, Tsuji MK, Volpe JJ 1998 Quantitative magnetic resonance imaging of brain development in premature and mature newborns. Ann Neurol 43:224-235

9. Inder TE, Huppi PS, Warfield S, Kikinis R, Zientara GP, Barnes PD, Jolesz F, Volpe JJ 1999 Periventricular white matter injury in the premature infant is followed by reduced cerebral cortical gray matter volume at term. Ann Neurol 46:755-760

10. Inder TE, Warfield SK, Wang H, Huppi PS, Volpe JJ 2005 Abnormal cerebral structure is present at term in premature infants. Pediatrics 115:286-294

11. Zacharia A, Zimine S, Lovblad KO, Warfield S, Thoeny H, Ozdoba C, Bossi E, Kreis R, Boesch C, Schroth G, Huppi PS 2006 Early assessment of brain maturation by MR imaging segmentation in neonates and premature infants. AJNR Am J Neuroradiol 27:972-977

12. Tolsa CB, Zimine S, Warfield SK, Freschi M, Sancho Rossignol A, Lazeyras F, Hanquinet S, Pfizenmaier M, Huppi PS 2004 Early alteration of structural and functional brain development in premature infants born with intrauterine growth restriction. Pediatr Res 56:132-138

13. Mewes AU, Huppi PS, Als H, Rybicki FJ, Inder TE, McAnulty GB, Mulkern RV, Robertson RL, Rivkin MJ, Warfield SK 2006 Regional brain development in serial magnetic resonance imaging of low-risk preterm infants. Pediatrics 118:23-33

14. Jarvenpaa T, Laakso MP, Rossi R, Koskenvuo M, Kaprio J, Raiha I, Kurki T, Laine M, Frisoni GB, Rinne JO 2004 Hippocampal MRI volumetry in cognitively discordant monozygotic twin pairs. J Neurol Neurosurg Psychiatry 75:116-120

15. Sullivan EV, Pfefferbaum A, Swan GE, Carmelli D 2001 Heritability of hippocampal size in elderly twin men: equivalent influence from genes and environment. Hippocampus 11:754-762

16. Sizonenko SV, Borradori-Tolsa C, Bauthay DM, Lodygensky G, Lazeyras F, Huppi P 2006 Impact of intrauterine growth restriction and glucocorticoids on brain development: insights using advanced magnetic resonance imaging. Mol Cell Endocrinol 254-255:163-171

17. Mallard C, Loeliger M, Copolov D, Rees S 2000 Reduced number of neurons in the hippocampus and the cerebellum in the postnatal guinea-pig following intrauterine growth-restriction. Neuroscience 100:327-333

18. Mallard EC, Rehn A, Rees S, Tolcos M, Copolov D 1999 Ventriculomegaly and reduced hippocampal volume following intrauterine growth-restriction: implications for the aetiology of schizophrenia. Schizophr Res 40:11-21

19. Warfield SK, Kaus M, Jolesz FA, Kikinis R 2000 Adaptive, template moderated, spatially varying statistical classification. Med Image Anal 4:43-55

20. Ashburner J, Friston KJ 2000 Voxel-based morphometry-the methods. Neuroimage 11:805-821

21. Sonesson SE, Fouron JC, Drblik SP, Tawile C, Lessard M, Skoll A, Guertin MC, Ducharme GR 1993 Reference values for Doppler velocimetric indices from the fetal and placental ends of the umbilical artery during normal pregnancy. J Clin Ultrasound 21:317-324

22. Wells WM III, Viola P, Atsumi H, Nakajima S, Kikinis R 1996 Multi-modal volume registration by maximization of mutual information. Med Image Anal 1:35-51

23. Duvernoy HM, Bourgouin P 1998 The human Hippocampus: Functional Anatomy, Vascularization and Serial Sections With MRI. Springer, Berlin, New York, pp $109-171$

24. Obenaus A, Yong-Hing CJ, Tong KA, Sarty GE 2001 A reliable method for measurement and normalization of pediatric hippocampal volumes. Pediatr Res 50:124-132

25. Pantel J, O'Leary DS, Cretsinger K, Bockholt HJ, Keefe H, Magnotta VA, Andreasen NC 2000 A new method for the in vivo volumetric measurement of the human hippocampus with high neuroanatomical accuracy. Hippocampus 10:752758

26. Buehler DM, Als H, Duffy FH, McAnulty GB, Liederman J 1995 Effectiveness of individualized developmental care for low-risk preterm infants: behavioral and electrophysiologic evidence. Pediatrics 96:923-932 
27. Brazelton TB 1973 Neonatal Behavioral Assessment Scale. Spastics International Medical Publications, Heinemann Medical, J. B. Lippincott, London Philadelphia, pp 1-66

28. Gimenez M, Junque C, Narberhaus A, Caldu X, Salgado-Pineda P, Bargallo N, Segarra D, Botet F 2004 Hippocampal gray matter reduction associates with memory deficits in adolescents with history of prematurity. Neuroimage 23:869-877

29. Isaacs EB, Lucas A, Chong WK, Wood SJ, Johnson CL, Marshall C, VarghaKhadem F, Gadian DG 2000 Hippocampal volume and everyday memory in children of very low birth weight. Pediatr Res 47:713-720

30. Nosarti C, Al-Asady MH, Frangou S, Stewart AL, Rifkin L, Murray RM 2002 Adolescents who were born very preterm have decreased brain volumes. Brain 125:1616-1623

31. Chen S, Xia W, Li L, Liu J, He Z, Zhang Z, Yan L, Zhang J, Hu D 2006 Gray matter density reduction in the insula in fire survivors with posttraumatic stress disorder: a voxel-based morphometric study. Psychiatry Res 146:65-72

32. Lodygensky GA, Rademaker K, Zimine S, Gex-Fabry M, Lieftink AF, Lazeyras F, Groenendaal F, de Vries LS, Huppi PS 2005 Structural and functional brain development after hydrocortisone treatment for neonatal chronic lung disease. Pediatrics 116:1-7
33. Szabo CA, Xiong J, Lancaster JL, Rainey L, Fox P 2001 Amygdalar and hippocampal volumetry in control participants: differences regarding handedness. AJNR Am J Neuroradiol 22:1342-1345

34. Feldman R, Eidelman AI 2006 Neonatal state organization, neuromaturation, motherinfant interaction, and cognitive development in small-for-gestational-age premature infants. Pediatrics 118:e869-e78

35. Pokorny J, Pecova Y, Trojan S, Langmeier M 1989 Hypoxia and development of interneurones of the rat hippocampus. Physiol Bohemoslov 38:215-222

36. Uno H, Eisele S, Sakai A, Shelton S, Baker E, DeJesus O, Holden J 1994 Neurotoxicity of glucocorticoids in the primate brain. Horm Behav 28:336-348

37. Seckl JR 1997 Glucocorticoids, feto-placental 11 beta-hydroxysteroid dehydrogenase type 2, and the early life origins of adult disease. Steroids 62:89-94

38. Goland RS, Jozak S, Warren WB, Conwell IM, Stark RI, Tropper PJ 1993 Elevated levels of umbilical cord plasma corticotropin-releasing hormone in growth-retarded fetuses. J Clin Endocrinol Metab 77:1174-1179

39. Phillips DI, Walker BR, Reynolds RM, Flanagan DE, Wood PJ, Osmond C, Barker DJ, Whorwood CB 2000 Low birth weight predicts elevated plasma cortisol concentrations in adults from 3 populations. Hypertension 35:1301-1306

40. Jorgenson LA, Wobken JD, Georgieff MK 2003 Perinatal iron deficiency alters apical dendritic growth in hippocampal CA1 pyramidal neurons. Dev Neurosci 25:412-420 